\title{
Plasma Gelsolin and Its Association with Mortality and Hospitalization in Chronic Hemodialysis Patients
}

\author{
Cesar Flores Gama ${ }^{a}$ Laura M. Rosales ${ }^{b}$ Georges Ouellet ${ }^{c}$ Yanna Dou $^{d}$ \\ Stephan Thijssen $^{b}$ Len Usvyat ${ }^{e}$ Hanjie Zhang $^{b}$ Viktoriya Kuntsevich ${ }^{f}$ \\ Nathan W. Levin ${ }^{f}$ Peter Kotankob, $f$ \\ ${ }^{a}$ Department of Nephrology, National Institute of Cardiology Ignacio Chávez, Mexico City, Mexico; ${ }^{\text {b } R e n a l ~ R e s e a r c h ~}$ \\ Institute, New York, NY, USA; ' Hôpital Maisonneuve-Rosemont, Montreal, QC, Canada; ${ }^{\text {d}}$ The Nephrology Center, The \\ First Affiliated Hospital of Zhengzhou University, Henan, China; ${ }^{~}$ Fresenius Medical Care North America, Waltham, \\ MA, and ${ }^{f}$ Icahn School of Medicine at Mount Sinai, New York, NY, USA
}

\section{Key Words}

Cytokines · Gelsolin · Hemodialysis · Inflammation · Uremic toxins · Free triiodothyronine · Hemodialysis · Mortality $\cdot$ Hospitalization

\footnotetext{
Abstract

Background: Human plasma gelsolin (pGSN) is an actinbinding protein that is secreted into the extracellular fluid, with the skeletal muscle and myocardial tissues being its major source. Depletion of pGSN has been shown to be related to a variety of inflammatory and clinical conditions. Methods: pGSN levels were prospectively determined in prevalent maintenance hemodialysis (HD) patients from 3 U.S. dialysis centers. Demographics (age, time since dialysis initiation, race, gender, body height and weight, comorbidities), inflammatory markers ( $C$ reactive protein, CRP; interleukin 6, IL-6), free triiodothyronine (fT3), and routine laboratory parameters were obtained. We performed Kaplan-Meier and Cox proportional hazard survival analysis for all-cause
}

and cardiovascular mortality, and recurrent event survival analysis for hospitalization. Results: We studied 153 patients; mean age was $60.5 \pm 14.7 ; 52 \%$ were males. The mean pGSN level was $6,617 \pm 1,789 \mathrm{mU} / \mathrm{ml}$. In univariate analysis, pGSN was positively correlated with body mass index $(r=$ $0.2, p=0.01)$, pre-HD serum albumin $(r=0.247, p=0.002)$, and pre-HD serum creatinine $(r=0.381, p<0.001)$, and inversely with age $(r=-0.286, p<0.001), \operatorname{CRP}(r=-0.311, p<$ $0.001)$, and IL-6 $(r=-0.317, p<0.001)$. In the adjusted analysis, the associations with CRP and creatinine were retained. pGSN levels tended to be lower in patients who died ( $p=$ 0.08). There was no association with all-cause or cardiovascular mortality, or all-cause hospitalization. Of note, fT3 was lower in patients who died $(p=0.001)$. Conclusions: Even though pGSN was inversely correlated with age, CRP and IL6 , suggesting that inflammation may influence pGSN, lower pGSN levels were not associated with hospitalization, allcause and cardio-vascular mortality in this patient population.

(c) 2017 S. Karger AG, Basel

\section{KARGER}

(c) 2017 S. Karger AG, Basel

E-Mail karger@karger.com

www.karger.com/bpu
Laura M. Rosales, MD

Renal Research Institute 315 East, 62nd Street, 4th Floor New York, NY 10065 (USA)

E-Mail laura.rosales@ rriny.com 


\section{Introduction}

While technical and clinical advances have improved morbidity and mortality in patients with chronic kidney disease (CKD), their outcomes continue to be poor, particularly in chronic hemodialysis (HD) patients [13].

Biomarkers such as inflammatory proteins are used frequently to identify patients at increased risk for adverse outcomes in a timely manner. Plasma gelsolin (pGSN) has been added to the growing list of biomarkers by showing its usefulness in predicting clinical outcomes in acute, severe [4-7] and chronic diseases [8-11]. GSN was first identified in cytoplasmic extracts as an actinscavenger protein, which in the presence of ionized calcium disassembles actin filaments and increases cytosolic fluidity [12-14]. GSN was found in a variety of mammalian tissues [15-17]. pGSN is a highly conserved, highmolecular, actin-binding protein, mainly secreted by myocytes [18]. pGSN functions as an actin-sequestering protein. After binding to actin, the pGSN-actin complex is quickly cleared from the circulation; pGSN also contains inflammatory and immune reactions, thus protecting the host from further damage [19, 20]. Emerging data demonstrate that pGSN, in addition to scavenging actin, may also bind and modulate inflammatory mediators and exogenous bacterial lipids, as well as promote the disposal of actin and phagocytic uptake of bacteria in human plasma and mouse models [20,21].

In summary, pGSN seems to play a key role in containing potentially overshooting host responses to sepsis, burns, trauma, and other clinical conditions. However, excessive actin exposure following extensive injury could lower pGSN levels, compromising containment of inflammation. The prognostic implications of low levels of pGSN before and after acute insults have been well documented $[7,22,23]$. More recently, pGSN has also been studied in CKD patients on HD [24, 25]. Previous studies have suggested that pGSN could be the link between malnutrition, inflammation, vascular calcification and mortality in HD patients [26, 27].

The correlation between low levels of free triiodothyronine (fT3), increased inflammation, and the presence of cardiovascular disease in the end-stage renal disease population has been firmly established [28-30]. Previous studies have not determined a causal relationship between fT3 and inflammation [30,31]. However, there is persistent association between low triiodothyronine levels and increased risk of death in long-term HD patients $[32,33]$. Measuring fT3 levels along with inflammatory proteins such as interleukin 6 (IL-6) and C-reactive protein (CRP) may provide useful information in planning trials of fT3 replacement.

In this prospective multicenter study in chronic HD patients, we aimed to expand the body of knowledge by exploring associations between pGSN and inflammatory markers, hospitalization and survival.

\section{Subjects and Methods}

We conducted a prospective cohort study in 3 dialysis clinics of the Renal Research Institute (RRI). The baseline period lasted 1 month for each clinic, and data were collected from January 1, 2010 to April 30, 2010. Patient outcomes were recorded during a follow-up period of 34 months. The primary outcome was allcause mortality; secondary outcome was all-cause hospitalization. Patients were categorized into tertiles of baseline pGSN levels.

We included HD patients aged 18 and above. Patients were excluded in cases of vascular access failure that would have prevented blood draws for pGSN determination. Within a month after providing informed consent, blood samples were drawn before (pre-HD) the mid-week HD session for the measurements of pGSN, IL-6, CRP, and fT3. Baseline clinical characteristics were collected on the first month of the study, and information on all-cause mortality and hospitalization events were retrieved on a monthly basis from medical records during the follow-up period.

The study was approved by the Institutional Review Board of Beth Israel Medical Center, New York, and conducted in accordance with the Helsinki Declaration. All patients gave informed consent.

\section{Biochemical Measurements}

pGSN level was determined using 2C4 Plasma Gelsolin ELISA kit (Critical Biologics Corporation, Cambridge, Mass., USA). fT3 was measured by direct chemiluminescence (ADVIA Centaur fT3 assay, Siemens, Deerfield, Ill., USA), CRP and complete blood count were measured by routine laboratory techniques; IL-6 was determined with the Quantikine ELISA kit (R\&D, Minneapolis, Minn., USA) at Spectra Clinical Research (Rockleigh, N.J., USA).

\section{Statistical Analysis}

Continuous variables were reported as mean and SD, or as medians with interquartile range, depending on their distribution. Pearson or Spearman correlations between pGSN and inflammatory markers were performed depending on their distribution. For survival analysis, Kaplan-Meier survival curves were constructed and survival was compared between tertiles of pGSN using the log-rank test. For multivariate time-to-death analysis, Cox proportional hazards models were created. Recurrent event analysis for hospitalization was conducted. The proportional hazard assumption was verified through graphic (log-log survival plots) and statistical approaches (goodness of fit and t-dependent variable approaches). Stepwise regression analysis was performed to identify variables associated with pGSN level including variables with a $p$ value $<0.05$. The variables used for adjustment were body mass index (BMI), diabetes, albumin, age, and IL-6. 
Table 1. Demographics and baseline patient characteristics

\begin{tabular}{|c|c|c|c|c|}
\hline Parameter & Total $(n=153)$ & Survivors $(\mathrm{n}=124)$ & Non survivors $(\mathrm{n}=29)$ & $\mathrm{p}$ value \\
\hline Age, years & $60.5 \pm 14.7$ & $59.1 \pm 14.8$ & $66.5 \pm 12.6$ & 0.01 \\
\hline Females, \% & $74(48.4)$ & $59(47.6)$ & $15(51.7)$ & 0.69 \\
\hline Race, \% & & & & 0.96 \\
\hline White & $9(5.9)$ & $7(5.6)$ & $2(6.9)$ & \\
\hline Black & $64(41.8)$ & $51(41.1)$ & $13(44.8)$ & \\
\hline Asian & $7(4.6)$ & $6(4.8)$ & $1(3.5)$ & \\
\hline Hispanic & $73(47.7)$ & $60(48.4)$ & $13(44.8)$ & \\
\hline $\mathrm{BMI}, \mathrm{kg} / \mathrm{m}^{2}$ & $28.4(23.7-32.5)$ & $28.5(23.7-32.4)$ & $26.9(23.6-33.5)$ & 0.73 \\
\hline Diabetes, \% & $79(51.6)$ & $59(47.6)$ & $20(69.0)$ & 0.04 \\
\hline Cardiovascular disease, $\%$ & $57(37.3)$ & $44(35.5)$ & $13(44.83)$ & 0.35 \\
\hline Hepatitis C infection, \% & $31(20.3)$ & $23(18.6)$ & $8(27.6)$ & 0.28 \\
\hline Dialysis vintage, years & $2.4(1.4-5.2)$ & $2.4(1.1-6.2)$ & $2.5(1.6-4.2)$ & 0.78 \\
\hline Vascular access n (\%) & & & & 0.006 \\
\hline AVF & $108(70.6)$ & $94(75.8)$ & $14(48.3)$ & \\
\hline AVG & $26(17)$ & $19(15.3)$ & $7(24.1)$ & \\
\hline Central venous catheter & $19(12.4)$ & $11(8.9)$ & $8(27.6)$ & \\
\hline Albumin, g/dl & $4.1(3.9-4.3)$ & $4.1(3.9-4.3)$ & $3.8(3.6-4.0)$ & $<0.001$ \\
\hline Phosphorus, mg/dl & $5.3(4.3-6.4)$ & $5.3(4.4-6.3)$ & $5.3(4.2-6.4)$ & 0.71 \\
\hline Creatinine, $\mathrm{mg} / \mathrm{dl}$ & $9.1 \pm 2.6$ & $9.3 \pm 2.5$ & $8.1 \pm 2.9$ & 0.03 \\
\hline nPCR, g/kg/day & $0.9(0.8-1.1)$ & $1.0(0.8-1.1)$ & $0.9(0.7-1.0)$ & 0.05 \\
\hline $\mathrm{eKt} / \mathrm{V}$ & $1.4(1.3-1.6)$ & $1.5(1.3-1.6)$ & $1.4(1.3-1.5)$ & 0.004 \\
\hline Hemoglobin, g/dl & $11.9(11-12.4)$ & $11.9(11.1-12.4)$ & $11.9(10.7-12.2)$ & 0.48 \\
\hline Ferritin, $\mu \mathrm{g} / \mathrm{l}$ & 703 (399-956) & $699.5(391-981)$ & 708 (590-919) & 0.54 \\
\hline $\mathrm{CRP}, \mathrm{mg} / \mathrm{l}$ & $6.8(3.3-13.8)$ & $6.1(3.3-12.6)$ & $9.5(3.5-44.8)$ & 0.08 \\
\hline IL-6, pg/ml & $2.1(2.1-5.5)$ & $2.1(2.1-5.1)$ & $2.1(2.1-11.7)$ & 0.16 \\
\hline NLR & $3.1(2.2-4.1)$ & $2.9(2.2-4.0)$ & $3.1(2.3-4.3)$ & 0.39 \\
\hline Triiodothyronine, $\mathrm{pg} / \mathrm{ml}$ & $2.4 \pm 0.4$ & $2.4 \pm 0.3$ & $2.2 \pm 0.4$ & 0.001 \\
\hline
\end{tabular}

Data are displayed as means \pm SDs, medians (interquartile ranges) or $\mathrm{n}(\%)$ as appropriate. $\mathrm{p}$ values resulted from chi-square tests.

$\mathrm{nPCR}=$ Normalized protein catabolic rate; $\mathrm{eKt} / \mathrm{V}=$ equilibrated Kt/V; $\mathrm{AVF}=$ arterio-venous fistula; $\mathrm{AVG}=$ arterio-venous graft; NLR = neutrophil-to-lymphocyte ratio.

Two-sided p values $<0.05$ were considered statistically significant. Statistical analysis was performed with STATA/SE version 12.1 (Stata-Corp, College Station, Tex., USA).

\section{Results}

We studied 153 patients; $48 \%$ were females, mean age was $60.5 \pm 14.7,79(51.6 \%)$ patients had diabetes, 57 (37.3\%) had a history of cardiovascular disease, and dialysis vintage was $2.4(1.4-5.2)$ years. The mean follow-up was 769 days. Patient characteristics are shown in table 1.

The mean pGSN level was $6,617 \pm 1,789 \mathrm{mU} / \mathrm{ml}$ and the distribution is shown in figure 1. In univariate analysis, pGSN was positively correlated with BMI $(r=0.200$, $\mathrm{p}=0.01)$, pre-HD serum albumin $(\mathrm{r}=0.247, \mathrm{p}=0.002)$, and creatinine $(\mathrm{r}=0.381, \mathrm{p}<0.001)$, and inversely with

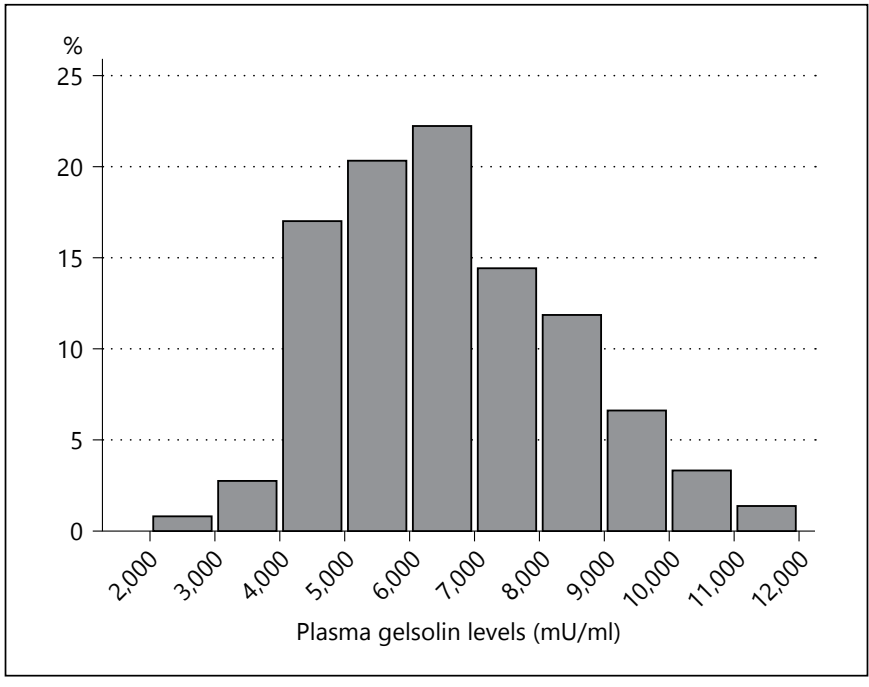

Fig. 1. Distribution of pre-HD pGSN levels. 
Fig. 2. Kaplan-Meier survival curves in patients stratified by pGSN levels.

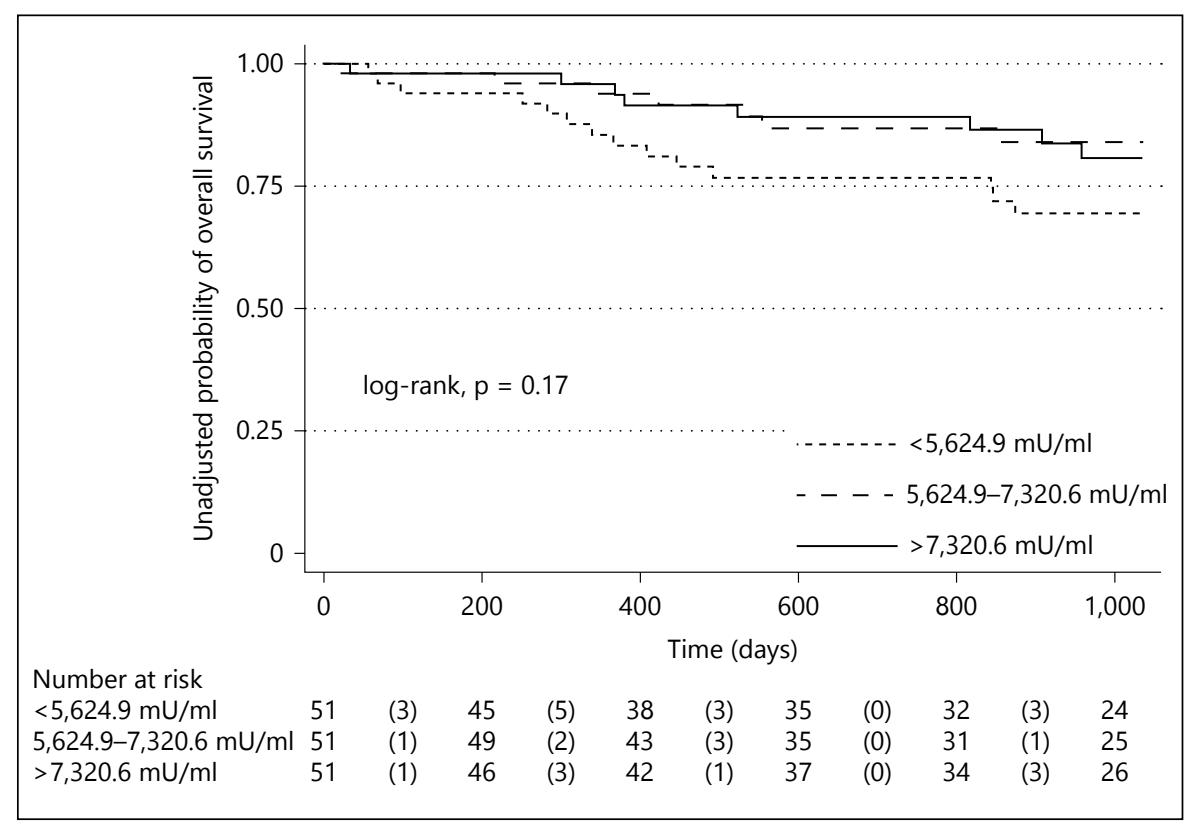

age $(\mathrm{r}=-0.286, \mathrm{p}<0.001)$, CRP $(\mathrm{r}=-0.311, \mathrm{p}<0.001)$, and IL-6 $(\mathrm{r}=-0.317, \mathrm{p}<0.001)$. In the adjusted analysis, the inverse relationship between CRP and pGSN was retained $(\beta=-23.8(-35.5$ to -12.1$), p<0.001)$, as was the positive correlation with pre-HD serum creatinine $(\beta=$ $258.1(162.0-354.3), \mathrm{p}<0.001)$.

\section{Mortality and Hospitalization}

Twenty-nine patients (19\%) died during the followup. The causes of death were cardiovascular $(\mathrm{n}=14)$, infectious $(\mathrm{n}=5)$, trauma $(\mathrm{n}=1)$, and unknown $(\mathrm{n}=9)$ with a median time to death of 380 days (283-554). Patients who died were older ( $67 \pm 13$ vs. $59 \pm 5$ years; $\mathrm{p}=0.01$ ), had a higher proportion of diabetes (69 vs. $47.6 \% ; \mathrm{p}=0.04)$, and central venous catheter use $(27.6$ vs. $8.9 \% ; \mathrm{p}=0.006)$, lower levels of albumin (3.8 (3.6$4.0)$ vs. $4.1(3.9-4.3) \mathrm{g} / \mathrm{dl} ; \mathrm{p}<0.001)$, lower equilibrated normalized protein catabolic rate $(0.9(0.7-1.0)$ vs. 1.0 $(0.8-1.1) \mathrm{g} / \mathrm{kg}$ body weight; $\mathrm{p}=0.05)$, lower equilibrated $\mathrm{Kt} / \mathrm{V}(1.4(1.3-1.5)$ vs. $1.5(1.3-1.6) ; \mathrm{p}=0.004)$, and lower fT3 $(2.2 \pm 0.4$ vs. $2.4 \pm 0.3 \mathrm{pg} / \mathrm{ml} ; \mathrm{p}=0.001)$, and a trend toward higher CRP (9.5 (3.5-44.8) vs. 6.1 (3.312.6) $\mathrm{mg} / \mathrm{dl}$; $\mathrm{p}=0.08)$.

Pre-dialysis pGSN level tended to be lower in those patients who died $(5,995 \pm 1,789$ vs. $6,722 \pm 1,775 \mathrm{mU} /$ $\mathrm{ml} ; \mathrm{p}=0.08$ ). Figure 2 shows a similar survival probability between groups according to pGSN tertiles (chi-square = 3.4 ; $\log$-rank $\mathrm{p}=0.17$ ). After adjustment for confounders, pGSN levels were associated with neither all-cause mor- tality (table 2) nor cardiovascular mortality (HR 0.99, 95\% CI 0.99-1.00; $\mathrm{p}=0.19$ ).

For hospitalization analysis, 7 patients with hospitalization related to kidney transplantation were excluded from the analysis, and 569 hospitalizations in 146 patients were recorded, 76 hospitalizations were related to infections (13.4\%), and 193 (33.9\%) to cardiovascular events, $23(4.0 \%)$ to dialysis access dysfunction, and 277 (48.7\%) to other causes (diabetes related, gastrointestinal complaints, electrolyte disturbances, pain, anemia, etc.). Neither in univariate (fig. 3) nor multivariate (table 3) analysis pGSN was associated with time to first all-cause hospitalization. In a subset analysis, pGSN was not associated with infection-related hospitalization (HR 1.00, 95\% CI 0.99-1.00; $\mathrm{p}=0.92$; table 4).

\section{Discussion}

The key findings of our study were a positive correlation of pGSN with BMI, albumin and creatinine and a negative correlation with diabetes and inflammatory markers. pGSN was not associated with mortality and hospitalization.

pGSN acts as an actin-binding protein limiting the inflammation to local tissues, minimizing their damage. More recently, additional studies have suggested that it can act as an inflammatory mediator in different clinical scenarios $[11,21,25,34]$. To the best of our knowledge, 
Fig. 3. Kaplan-Meier analysis of time to first all-cause hospitalization.

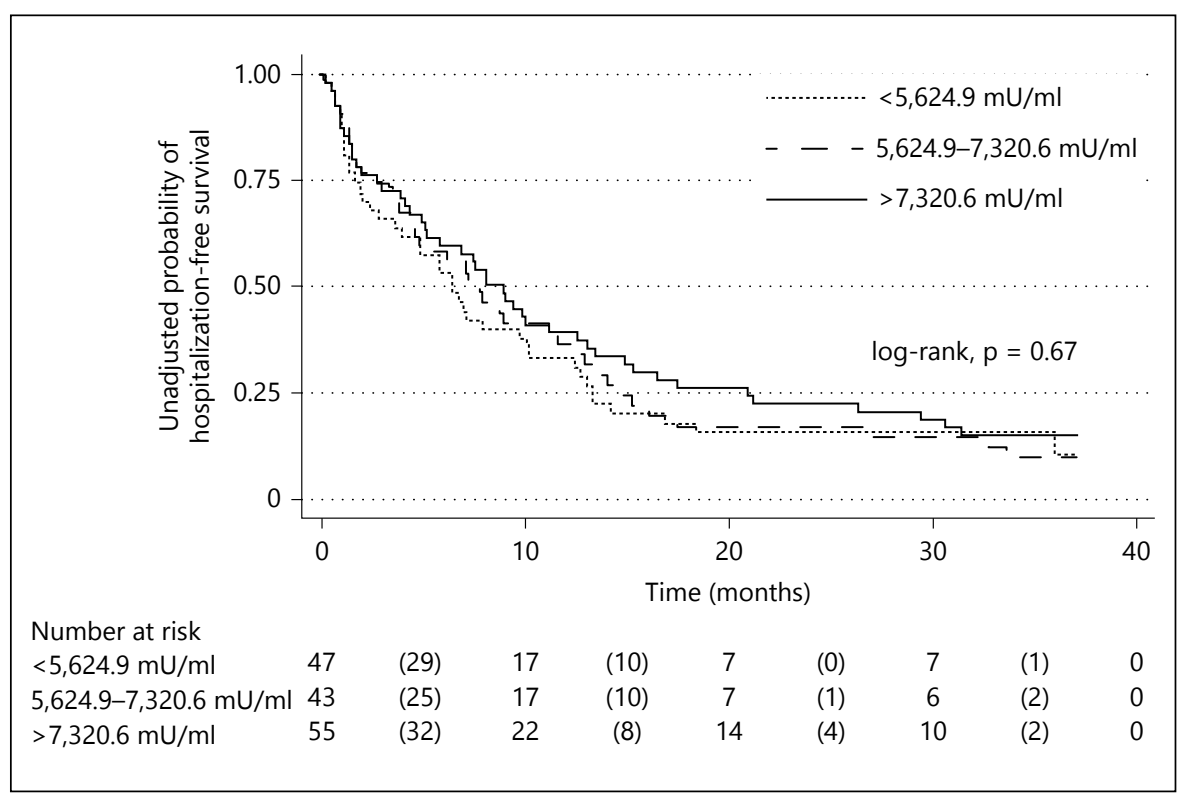

Table 2. Univariate and multivariate analyses of predictors of all-cause and cardiovascular mortality

\begin{tabular}{|c|c|c|c|c|c|c|}
\hline \multirow[t]{2}{*}{ Parameter } & \multicolumn{2}{|c|}{ Univariate analysis $^{\mathrm{a}}$} & \multicolumn{2}{|c|}{ Univariate analysis $^{\mathrm{b}}$} & \multicolumn{2}{|c|}{ Multivariate analysis ${ }^{\mathrm{c}}$} \\
\hline & HR (95\% CI) & $\mathrm{p}$ value & HR (95\% CI) & $\mathrm{p}$ value & HR (95\% CI) & $\mathrm{p}$ value \\
\hline Age, years & $1.03(1.00-1.06)$ & 0.02 & $1.03(1.00-1.06)$ & 0.05 & $1.02(0.99-1.07)$ & 0.21 \\
\hline Albumin, g/dl & $0.25(0.12-0.51)$ & $<0.001$ & $0.23(0.10-0.51)$ & $<0.001$ & $0.35(0.11-1.08)$ & 0.07 \\
\hline Vintage, years & $0.93(0.83-1.05)$ & 0.27 & & & $0.93(0.78-1.10)$ & 0.39 \\
\hline Cardiovascular disease & $1.32(0.63-2.74)$ & 0.46 & & & $1.62(0.57-4.64)$ & 0.36 \\
\hline IL-6, pg/ml & $1.02(1.00-1.04)$ & 0.05 & & & $1.03(1.00-1.06)$ & 0.05 \\
\hline \multicolumn{7}{|l|}{$\mathrm{pGSN}, \mathrm{mU} / \mathrm{ml}$} \\
\hline$>7,320.6$ & Ref & & & & Ref & \\
\hline $5,624.9-7,320.6$ & $1.85(0.77-4.40)$ & 0.17 & & & $0.75(0.17-6.19)$ & 0.95 \\
\hline$<5,624.9$ & $0.88(0.32-2.42)$ & 0.80 & & & $1.81(0.17-3.37)$ & 0.71 \\
\hline Diabetes mellitus & $2.15(0.98-4.73)$ & 0.06 & & & $1.29(0.45-3.72)$ & 0.64 \\
\hline Catheter & $3.92(1.72-8.89)$ & 0.001 & $4.01(1.74-9.30)$ & 0.001 & $2.77(0.77-10.0)$ & 0.12 \\
\hline Male & $0.86(0.41-1.78)$ & 0.68 & & & $1.24(0.43-3.57)$ & 0.69 \\
\hline NLR & $1.09(0.96-1.25)$ & 0.18 & & & $1.12(0.94-1.33)$ & 0.22 \\
\hline CRP, mg/l & $1.02(1.01-1.03)$ & 0.003 & & & $1.01(0.99-1.03)$ & 0.09 \\
\hline Triiodothyronine, $\mathrm{pg} / \mathrm{ml}$ & $0.25(0.09-0.69)$ & 0.008 & & & $0.29(0.07-1.26)$ & 0.10 \\
\hline
\end{tabular}

${ }^{a}$ Univariate analysis for all-cause mortality.

${ }^{\mathrm{b}}$ Univariate analysis for cardiovascular mortality.

${ }^{c}$ Multivariate analysis for all-cause mortality adjusted for age, gender, BMI, cause of end-stage renal disease, vascular access and biomarkers of inflammation.

NLR = Neutrophil-to-lymphocyte; Ref = pGSN reference group.

only 2 previous studies have investigated the relationship between pGSN and outcomes in CKD patients [25,35]. We corroborated a previous study by Lee et al. [35] who showed in 150 incident HD patients that pGSN was directly associated with nutritional markers such as albu- min and serum creatinine and inversely with age and inflammatory markers. In a larger sample, Lee et al. [35] performed a case-control analysis, where they found that pGSN levels were significantly lower in 114 patients who died within 1 year of dialysis initiation, than in 109 survi- 
Table 3. Univariate and multivariate analyses of predictors of first all-cause hospitalization

\begin{tabular}{|c|c|c|c|c|}
\hline \multirow[t]{2}{*}{ Variable } & \multicolumn{2}{|c|}{ Univariate analysis } & \multicolumn{2}{|c|}{ Multivariate analysis } \\
\hline & HR (95\% CI) & $\mathrm{p}$ value & HR (95\% CI) & $\mathrm{p}$ value \\
\hline Age, years & $1.02(1.00-1.03)$ & 0.02 & $1.01(1.00-1.03)$ & 0.05 \\
\hline Albumin, g/dl & $0.51(0.34-0.78)$ & 0.002 & $0.56(0.37-0.87)$ & 0.009 \\
\hline Vintage, years & $0.97(0.93-1.02)$ & 0.30 & & \\
\hline Cardiovascular disease & $0.96(0.66-1.41)$ & 0.85 & & \\
\hline IL-6, pg/ml & $1.01(0.99-1.02)$ & 0.38 & & \\
\hline \multicolumn{5}{|l|}{$\mathrm{pGSN}, \mathrm{mU} / \mathrm{ml}$} \\
\hline$>7,320.6$ & Ref & & & \\
\hline $5,624.9-7,320.6$ & $1.11(0.74-1.69)$ & 0.61 & & \\
\hline$<5,624.9$ & $1.15(0.73-1.82)$ & 0.54 & & \\
\hline Diabetes mellitus & $1.40(0.98-2.02)$ & 0.15 & & \\
\hline Catheter & $1.57(0.99-2.49)$ & 0.06 & $1.45(0.88-2.39)$ & 0.14 \\
\hline Male & $0.98(0.68-1.41)$ & 0.92 & & \\
\hline NLR & $1.07(1.00-1.16)$ & 0.06 & & \\
\hline CRP, mg/l & $1.00(0.99-1.01)$ & 0.37 & & \\
\hline Triiodothyronine, pg/ml & $0.59(0.35-0.99)$ & 0.05 & & \\
\hline
\end{tabular}

NLR = Neutrophil-to-lymphocyte ratio; $\operatorname{Ref}=$ pGSN reference group .

vors. In contrast, we did not find a relationship between pGNS levels and all-cause or cardiovascular mortality. Of note, there are some differences in the populations. First, our study included only prevalent patients (median vintage of 2.4 years (1.4-5.2)), whereas Lee's study enrolled only incident patients. Other differences relate to race (Whites 6.9 vs. $53.1 \%$ ), lower prevalence of catheter (12.4 vs. $58.3 \%)$, higher levels of serum albumin $(4.1 \mathrm{~g} / \mathrm{dl}(3.9-$ $4.3)$ vs. $3.2 \pm 0.6)$ and creatinine $(9.1 \pm 2.6$ vs. $5.5 \pm 2.6$ $\mathrm{mg} / \mathrm{dl}$ ). Additionally, pGSN levels in our study were measured by ELISA as opposed to a functional fluorimetric assay used by Lee et al. [36], which may make a comparison difficult [37].

Cardiovascular disease is the most common cause of death in patients on chronic dialysis [3, 38, 39]. It is tempting to speculate that pGSN may be involved in the pathogenesis of cardiovascular disease because of its interaction with osteopontin and platelet function [40-42]. More recently, Chiou et al. [25] in 184 prevalent HD patients found that lower levels of pGNS were associated with the progression of aortic arch calcification, which has been associated with cardiovascular mortality [43, 44]. However, in our study, we did not find an association between pGNS and cardiovascular mortality. Interestingly, Chiou et al. [25] reported pGSN levels about one seventh of our lower tertile, and a lower BMI levels, which could be explained by the differences in the studied population.

pGSN and Its Association with Mortality and Hospitalization in HD Patients
Table 4. Multivariate analysis of predictors of infection-related hospitalization

\begin{tabular}{llc}
\hline Variable & HR $(95 \% \mathrm{CI})$ & p value \\
\hline Age, years & $0.98(0.95-1.01)$ & 0.17 \\
Albumin, g/dl & $0.38(0.17-0.82)$ & 0.01 \\
Vintage, years & $1.05(0.96-1.14)$ & 0.29 \\
Cardiovascular disease & $1.76(0.92-3.34)$ & 0.09 \\
IL-6, pg/ml & $1.02(0.99-1.06)$ & 0.12 \\
pGSN, mU/ml & $1.00(0.99-1.00)$ & 0.92 \\
Diabetes mellitus & $4.92(2.23-10.88)$ & $<0.001$ \\
Catheter & $4.17(2.04-8.53)$ & $<0.001$ \\
Male & $0.93(0.55-2.12)$ & 0.82 \\
NLR & $0.88(0.75-1.03)$ & 0.10 \\
CRP, mg/l & $0.99(0.98-1.01)$ & 0.27 \\
Triiodothyronine, pg/ml & $1.03(0.30-3.61)$ & 0.96 \\
\hline
\end{tabular}

NLR = Neutrophil-to-lymphocyte ratio.

Even though we did not intend to study fT3 outcomes, our results corroborate recent investigations [32, 45] showing an association of low fT3 levels and an increased risk of death in long-term dialysis patients.

The major limitation of our study is the fact that pGSN was measured only once. It would be important to study the predictive usefulness of repeated pGSN measurements. From the literature, it is noticeable that pGSN levels could differ between populations and vary by gen- 
der, age, and ethnicity. It is also important to standardize the method of pGSN measurement.

In summary, we have shown that pGSN was directly associated with BMI, serum albumin and creatinine, and was inversely associated with age, CRP and IL-6. Patients who died during follow-up tended to have lower levels of pGSN, but after adjusting for confounding variables, pGSN was not associated with all-cause or cardiovascular mortality. In addition, pGSN was not associated with all-cause and infection-related hospitalization.

\section{Disclosure Statement}

Financial support and sponsorship: RRI. P.K. holds stock in Fresenius Medical Care.

\section{References}

1 Saran R, Li Y, Robinson B, Ayanian J, Balkrishnan R, Bragg-Gresham J, Chen JT, Cope E, Gipson D, He K, Herman W, Heung M, Hirth RA, Jacobsen SS, Kalantar-Zadeh K, Kovesdy CP, Leichtman AB, Lu Y, Molnar MZ, Morgenstern H, Nallamothu B, O'Hare AM, Pisoni R, Plattner B, Port FK, Rao P, Rhee CM, Schaubel DE, Selewski DT, Shahinian V, Sim JJ, Song P, Streja E, Kurella Tamura M, Tentori F, Eggers PW, Agodoa LY, Abbott KC: US renal data system 2014 annual data report: epidemiology of kidney disease in the United States. Am J Kidney Dis 2015;66(1 suppl 1):Svii, S1-S305.

2 Genovesi S, Valsecchi MG, Rossi E, Pogliani D, Acquistapace I, De Cristofaro V, Stella A, Vincenti A: Sudden death and associated factors in a historical cohort of chronic haemodialysis patients. Nephrol Dial Transplant 2009;24:2529-2536.

3 Collins AJ, Li S, Ma JZ, Herzog C: Cardiovascular disease in end-stage renal disease patients. Am J Kidney Dis 2001;38(4 suppl 1):S26-S29.

4 Lind SE, Smith DB, Janmey PA, Stossel TP: Depression of gelsolin levels and detection of gelsolin-actin complexes in plasma of patients with acute lung injury. Am Rev Respir Dis 1988;138:429-434.

5 Mounzer KC, Moncure M, Smith YR, Dinubile MJ: Relationship of admission plasma gelsolin levels to clinical outcomes in patients after major trauma. Am J Respir Crit Care Med 1999;160(5 pt 1):1673-1681.

6 Huang LF, Yao YM, Li JF, Dong N, Liu C, Yu Y, He LX, Sheng ZY: Reduction of plasma gelsolin levels correlates with development of multiple organ dysfunction syndrome and fatal outcome in burn patients. PLoS One 2011; 6:e25748.

7 Wang H, Cheng B, Chen Q, Wu S, Lv C, Xie G, Jin Y, Fang X: Time course of plasma gelsolin concentrations during severe sepsis in critically ill surgical patients. Crit Care 2008; 12:R106.

8 Guo XC, Luo BY, Li XF, Yang DG, Zheng XN, Zhang K: Plasma gelsolin levels and 1-year mortality after first-ever ischemic stroke. J Crit Care 2011;26:608-612.

9 Kulakowska A, Drozdowski W, Sadzynski A, Bucki R, Janmey PA: Gelsolin concentration in cerebrospinal fluid from patients with multiple sclerosis and other neurological disorders. Eur J Neurol 2008;15:584-588.

10 Osborn TM, Verdrengh M, Stossel TP, Tarkowski A, Bokarewa M: Decreased levels of the gelsolin plasma isoform in patients with rheumatoid arthritis. Arthritis Res Ther 2008; 10:R117.

11 Güntert A, Campbell J, Saleem M, O’Brien DP, Thompson AJ, Byers HL, Ward MA, Lovestone S: Plasma gelsolin is decreased and correlates with rate of decline in alzheimer's disease. J Alzheimers Dis 2010;21:585-596.

12 Yin HL, Stossel TP: Control of cytoplasmic actin gel-sol transformation by gelsolin, a calcium-dependent regulatory protein. Nature 1979;281:583-586.

13 Wang LL, Bryan J: Isolation of calcium-dependent platelet proteins that interact with actin. Cell 1981;25:637-649.

14 Lee WM, Galbraith RM: The extracellular actin-scavenger system and actin toxicity. $\mathrm{N}$ Engl J Med 1992;326:1335-1341.

15 Yin HL, Albrecht JH, Fattoum A: Identification of gelsolin, a Ca2+-dependent regulatory protein of actin gel-sol transformation, and its intracellular distribution in a variety of cells and tissues. J Cell Biol 1981;91(3 pt 1):901906.

16 Lind SE, Yin HL, Stossel TP: Human platelets contain gelsolin. A regulator of actin filament length. J Clin Invest 1982;69:1384-1387.

17 Yin HL, Kwiatkowski DJ, Mole JE, Cole FS: Structure and biosynthesis of cytoplasmic and secreted variants of gelsolin. J Biol Chem 1984;259:5271-5276.

18 Kwiatkowski DJ, Mehl R, Izumo S, NadalGinard B, Yin HL: Muscle is the major source of plasma gelsolin. J Biol Chem 1988;263: 8239-8243.

19 Bucki R, Georges PC, Espinassous Q, Funaki M, Pastore JJ, Chaby R, Janmey PA: Inactivation of endotoxin by human plasma gelsolin. Biochemistry 2005;44:9590-9597.

20 Dinubile MJ: Plasma gelsolin: in search of its raison d'etre. Focus on 'modifications of cellular responses to lysophosphatidic acid and platelet-activating factor by plasma gelsolin'. Am J Physiol Cell Physiol 2007;292:C1240C1242.
21 Bucki R, Byfield FJ, Kulakowska A, McCormick ME, Drozdowski W, Namiot Z, Hartung T, Janmey PA: Extracellular gelsolin binds lipoteichoic acid and modulates cellular response to proinflammatory bacterial wall components. J Immunol 2008;181:4936-4944.

22 Suhler E, Lin W, Yin HL, Lee WM: Decreased plasma gelsolin concentrations in acute liver failure, myocardial infarction, septic shock, and myonecrosis. Crit Care Med 1997;25: 594-598.

23 DiNubile MJ, Stossel TP, Ljunghusen OC, Ferrara JL, Antin JH: Prognostic implications of declining plasma gelsolin levels after allogeneic stem cell transplantation. Blood 2002; 100:4367-4371.

24 Lee PS, Patel SR, Christiani DC, Bajwa E, Stossel TP, Waxman AB: Plasma gelsolin depletion and circulating actin in sepsis: a pilot study. PLoS One 2008;3:e3712.

25 Chiou TT, Liao SC, Kao YY, Lee WC, Lee YT, Ng HY, Lee PS, Lee CT: Gelsolin and progression of aortic arch calcification in chronic hemodialysis patients. Int J Med Sci 2016;13: 92-98.

26 Lee PS, Bhan I, Thadhani R: The potential role of plasma gelsolin in dialysis-related proteinenergy wasting. Blood Purif 2010;29:99-101.

27 Fouque D, Kalantar-Zadeh K, Kopple J, Cano N, Chauveau P, Cuppari L, Franch H, Guarnieri G, Ikizler TA, Kaysen G, Lindholm B, Massy Z, Mitch W, Pineda E, Stenvinkel P, Treviño-Becerra A, Wanner C: A proposed nomenclature and diagnostic criteria for protein-energy wasting in acute and chronic kidney disease. Kidney Int 2008;73:391-398.

28 Zoccali C, Benedetto F, Mallamaci F, Tripepi G, Cutrupi S, Pizzini P, Malatino LS, Bonanno G, Seminara G: Low triiodothyronine and cardiomyopathy in patients with end-stage renal disease. J Hypertens 2006;24:20392046.

29 Carrero JJ, Qureshi AR, Axelsson J, Yilmaz MI, Rehnmark S, Witt MR, Bárány P, Heimbürger O, Suliman ME, Alvestrand A, Lindholm B, Stenvinkel P: Clinical and biochemical implications of low thyroid hormone levels (total and free forms) in euthyroid patients with chronic kidney disease. J Intern Med 2007;262:690-701. 
30 Enia G, Panuccio V, Cutrupi S, Pizzini P, Tripepi G, Mallamaci F, Zoccali C: Subclinical hypothyroidism is linked to micro-inflammation and predicts death in continuous ambulatory peritoneal dialysis. Nephrol Dial Transplant 2007;22:538-544.

31 Zoccali C, Tripepi G, Cutrupi S, Pizzini P, Mallamaci F: Low triiodothyronine: a new facet of inflammation in end-stage renal disease. J Am Soc Nephrol 2005; 16:2789-2795.

$32 \mathrm{Xu} \mathrm{H}$, Brusselaers N, Lindholm B, Zoccali C, Carrero JJ: Thyroid function test derangements and mortality in dialysis patients: a systematic review and meta-analysis. Am J Kidney Dis 2016;pii:S0272-6386(16)30348-1.

33 Rhee CM, Kim S, Gillen DL, Oztan T, Wang J, Mehrotra R, Kuttykrishnan S, Nguyen DV, Brunelli SM, Kovesdy CP, Brent GA, Kalantar-Zadeh K: Association of thyroid functional disease with mortality in a national cohort of incident hemodialysis patients. J Clin Endocrinol Metab 2015;100:1386-1395.

34 Yang Z, Chiou TT, Stossel TP, Kobzik L: Plasma gelsolin improves lung host defense against pneumonia by enhancing macrophage NOS3 function. Am J Physiol Lung Cell Mol Physiol 2015;309:L11-L16.

35 Lee PS, Sampath K, Karumanchi SA, Tamez $\mathrm{H}$, Bhan I, Isakova T, Gutierrez OM, Wolf M,
Chang Y, Stossel TP, Thadhani R: Plasma gelsolin and circulating actin correlate with hemodialysis mortality. J Am Soc Nephrol 2009; 20:1140-1148.

36 Lee PS, Drager LR, Stossel TP, Moore FD, Rogers SO: Relationship of plasma gelsolin levels to outcomes in critically ill surgical patients. Ann Surg 2006;243:399-403.

37 Kouyama T, Mihashi K: Fluorimetry study of $\mathrm{n}$-(1-pyrenyl)iodoacetamide-labelled f-actin. Local structural change of actin protomer both on polymerization and on binding of heavy meromyosin. Eur J Biochem 1981;114: 33-38.

38 Toussaint ND, Kerr PG: Vascular calcification and arterial stiffness in chronic kidney disease: implications and management. Nephrology (Carlton) 2007;12:500-509.

39 Johnson DW, Craven AM, Isbel NM: Modification of cardiovascular risk in hemodialysis patients: an evidence-based review. Hemodial Int 2007;11:1-14.

40 Chellaiah M, Hruska K: Osteopontin stimulates gelsolin-associated phosphoinositide levels and phosphatidylinositol triphosphatehydroxyl kinase. Mol Biol Cell 1996;7:743753.

41 Chellaiah M, Kizer N, Silva M, Alvarez U, Kwiatkowski D, Hruska KA: Gelsolin defi- ciency blocks podosome assembly and produces increased bone mass and strength. J Cell Biol 2000;148:665-678.

42 Osborn TM, Dahlgren C, Hartwig JH, Stossel TP: Modifications of cellular responses to lysophosphatidic acid and platelet-activating factor by plasma gelsolin. Am J Physiol Cell Physiol 2007;292:C1323-C1330.

43 Noordzij M, Cranenburg EM, Engelsman LF, Hermans MM, Boeschoten EW, Brandenburg VM, Bos WJ, Kooman JP, Dekker FW, Ketteler M, Schurgers LJ, Krediet RT, Korevaar JC; NECOSAD Study Group: Progression of aortic calcification is associated with disorders of mineral metabolism and mortality in chronic dialysis patients. Nephrol Dial Transplant 2011;26:16621669.

44 Iribarren C, Sidney S, Sternfeld B, Browner WS: Calcification of the aortic arch: risk factors and association with coronary heart disease, stroke, and peripheral vascular disease. JAMA 2000;283:2810-2815.

45 Fragidis S, Sombolos K, Thodis E, Panagoutsos S, Mourvati E, Pikilidou M, Papagianni A, Pasadakis P, Vargemezis V: Low T3 syndrome and long-term mortality in chronic hemodialysis patients. World J Nephrol 2015; $4: 415-422$. 